\title{
Game-Theoretical Model of the Voluntary Use of Insect Repellents to Prevent Zika Fever
}

\author{
Jabili Angina ${ }^{1} \cdot$ Anish Bachhu ${ }^{1} \cdot$ Eesha Talati $^{1} \cdot$ Rishi Talati $^{1} \cdot$ Jan Rychtár $^{2}$ (D) \\ Dewey Taylor ${ }^{2}$ (iD
}

Accepted: 10 December 2021 / Published online: 30 January 2022

(c) The Author(s), under exclusive licence to Springer Science+Business Media, LLC, part of Springer Nature 2021

\begin{abstract}
Zika fever is an emerging mosquito-borne disease. While it often causes no or only mild symptoms that are similar to dengue fever, Zika virus can spread from a pregnant woman to her baby and cause severe birth defects. There is no specific treatment or vaccine, but the disease can be mitigated by using several control strategies, generally focusing on the reduction in mosquitoes or mosquito bites. In this paper, we model Zika virus transmission and incorporate a game-theoretical approach to study a repeated population game of DEET usage to prevent insect bites. We show that the optimal use effectively leads to disease elimination. This result is robust and not significantly dependent on the cost of the insect repellents.
\end{abstract}

Keywords Zika virus · Nash equilibrium · Game theory · Vector-borne diseases · Insect repellent

\section{Introduction}

Zika virus (ZIKV) is an emerging mosquito-borne flavivirus [34]. ZIKV is transmitted to humans through the bites of infected Aedes mosquitoes, including A. aegypti and A. albopictus [2]. Recent studies show that ZIKV can be transmitted between humans via sexual contact or by blood transfusions [32].

ZIKV infection is predominantly a mild or asymptomatic dengue-like disease [29]. ZIKV infection can lead to Guillain-Barré Syndrome, microcephaly and other severe birth defects [37].

In the memory of J.V.

Jan Rychtáŕ

rychtarj@vcu.edu

1 Department of Biology, Virginia Commonwealth University, Richmond, VA 23284-2012, USA

2 Department of Mathematics and Applied Mathematics, Virginia Commonwealth University, Richmond, VA 23284-2014, USA 
There is currently no vaccine, specific treatment, or fast diagnostic test is available to treat, prevent, or diagnose ZIKV infection [33]. ZIKV mitigation is closely associated with the reduction in the presence and abundance of $A$. aegypti [9]. On the individual level, the best way to control the spread of ZIKV is to reduce sexual transmissions and avoid mosquito bites [62]. This can be achieved by avoiding unprotected sex [14,59], using mosquito repellents [36], bed nets [57], window screens [42], and air conditioning [62]. The climate changes may be behind the recent rise of ZIKV and other Aedes-borne infections [64-66].

ZIKV received considerable attention from mathematical modelers; see for example [2, $3,11,17,26,43,45,47,52,61,71,73,74]$.

Starting with [10], game theory has been increasingly applied to help with the modeling of the prevention of diseases such as African trypanosomiases [24], chikungunya [40], Ebola [13], Hepatitis C [67], meningitis [50], monkeypox [8], toxoplasmosis [70] and others; see $[18,75]$ for recent reviews.

In this paper, we build on the work of [12,72]. We show their compartmental ODE model in Sect. 2. The main contribution of this paper is the use game theory to model ZIKV prevention by a voluntary use of insect repellents. The game-theoretical framework is introduced in Sect. 2.3 where we define a population game played by susceptible individuals who repeatedly decide whether to use DEET or not. Our main results, including the game theory analysis, are presented in Sect. 4. We give exact formulas for the minimal DEET coverage needed for ZIKV elimination. We also give numerical values for the Nash equilibria, i.e., the solution of the game and the optimal voluntary use of DEET to prevent the spread of ZIKV through vector bites. We show that the Nash equilibrium is high enough and thus the voluntary use of DEET can significantly contribute to ZIKV elimination.

\section{Model}

\subsection{Compartmental Model}

We adapt an SIR-SI compartmental ODE model of ZIKV dynamics originally introduced in [12] and extended in [72].

The total human population at time $t, N_{h}(t)$, is divided into susceptible, $S_{h}(t)$, infectious, $I_{h}(t)$, and recovered, $R_{h}(t)$. The mosquito population, $N_{v}(t)$, is divided into susceptible, $S_{v}(t)$, and infectious, $I_{v}(t)$.

The basic model, without any control measures, is as follows. For simplicity, we assume no vertical transmission and thus all humans are recruited, at rate $\Lambda_{h}$ as susceptible. The susceptible individuals can be infected in one of the following ways: (1) directly through contact with an infected individual which happens at rate $\beta_{h h}$, or (2) through a bite by an infected mosquito, the effective mosquito-to-human transmission rate will be denoted $\beta_{v h}$. The infectious individuals naturally recover at a rate of $\gamma$. Recovered individuals are assumed to have acquired a permanent immunity. We assume no disease-induced mortality and denote the natural death rate by $\mu_{h}$.

The mosquito recruitment rate is $\Lambda_{v}$. We again assume that there is no vertical transmission and all mosquitoes are born susceptible. The mosquito natural death rate is $\mu_{v}$. Mosquitoes are infected via contact with infected humans at a rate of $\beta_{h v}$.

There are four control measures:

1. The bite control, $c_{b}$, such as using the insect repellent. This control limits the humanto-mosquito and mosquito-to-human contact rate and causes the effective transmission 


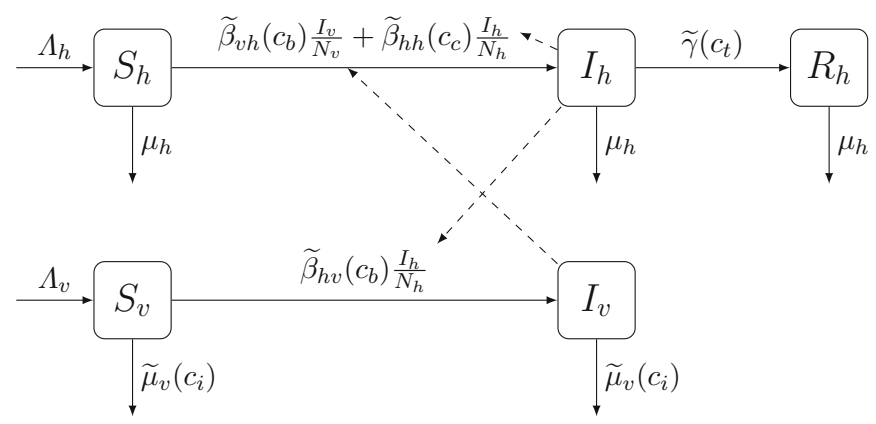

Fig. 1 Scheme of the ODE model for ZIKV transmission. Full arrows denote transitions between the compartments. The letters next to the arrows specify the per capita rates of the transitions. The dashed arrows show the influence on transmission rates

rates to be $\widetilde{\beta}_{h v}\left(c_{b}\right)=\left(1-c_{b}\right) \beta_{h v}$ and $\widetilde{\beta}_{v h}\left(c_{b}\right)=\left(1-c_{b}\right) \beta_{v h}$, respectively. Here, we use a linear dependence since, at least in the first approximation, being unprotected for double the time doubles the probability of transmission. We note, however, that other functions may be more appropriate.

2. The human-to-human contact control, $c_{c}$, such as the use of condoms. This control causes the effective human-to-human transmission rate to be $\widetilde{\beta}_{h h}\left(c_{c}\right)=\left(1-c_{c}\right) \beta_{h h}$. As above, we use a linear dependence since, at least in the first approximation, being unprotected in twice as many interactions doubles the probability of transmission. We note, however, that other functions may be more appropriate.

3. The treatment control, $c_{t}$, which causes recovery to progress at a faster rate $\tilde{\gamma}\left(c_{t}\right)=$ $\gamma+c_{t} \gamma_{h, t}$.

4. The insecticide control, $c_{i}$, which increases the mosquito death rate to $\tilde{\mu}_{v}\left(c_{i}\right)=\mu_{v}+$ $c_{i} \mu_{v, i}$.

For simplicity, all control measures are assumed to be constants and in the interval $[0,1]$.

The dynamics of the compartmental ODE model are summarized in Fig. 1. See Table 1 for a summary of the notation and values of the parameters.

The model in Fig. 1, which is a special case of a system considered in [76], yields the following differential equations.

$$
\begin{aligned}
\frac{\mathrm{d} S_{h}}{\mathrm{~d} t} & =\Lambda_{h}-\left(\widetilde{\beta}_{v h}\left(c_{b}\right) \frac{I_{v}}{N_{v}}+\widetilde{\beta}_{h h}\left(c_{c}\right) \frac{I_{h}}{N_{h}}+\mu_{h}\right) S_{h} \\
\frac{\mathrm{d} I_{h}}{\mathrm{~d} t} & =\left(\widetilde{\beta}_{v h}\left(c_{b}\right) \frac{I_{v}}{N_{v}}+\widetilde{\beta}_{h h}\left(c_{c}\right) \frac{I_{h}}{N_{h}}\right) S_{h}-\left(\mu_{h}+\widetilde{\gamma}\left(c_{t}\right)\right) I_{h} \\
\frac{\mathrm{d} R_{h}}{\mathrm{~d} t} & =\widetilde{\gamma}\left(c_{t}\right) I_{h}-\mu_{h} R_{h} \\
\frac{\mathrm{d} S_{v}}{\mathrm{~d} t} & =\Lambda_{v}-\left(\widetilde{\beta}_{h v}\left(c_{b}\right) \frac{I_{h}}{N_{h}}+\widetilde{\mu}_{v}\left(c_{i}\right)\right) S_{v} \\
\frac{\mathrm{d} I_{v}}{\mathrm{~d} t} & =\widetilde{\beta}_{h v}\left(c_{b}\right) \frac{I_{h}}{N_{h}} S_{v}-\tilde{\mu}_{v}\left(c_{i}\right) I_{v}
\end{aligned}
$$


Table 1 Model parameters and notation

\begin{tabular}{|c|c|c|c|}
\hline Notation & Meaning & Base value & References \\
\hline$\Lambda_{h}$ & Human recruitment rate & $\frac{0.01392}{365}$ & {$[77]$} \\
\hline$\Lambda_{v}$ & Mosquito recruitment rate & 3000 & [4] \\
\hline$\mu_{h}$ & Human natural death rate & $\frac{1}{74 \cdot 365}$ & {$[23]$} \\
\hline$\mu_{v}$ & Mosquito natural death rate & $\frac{1}{11}$ & {$[60]$} \\
\hline$\gamma$ & Natural recovery rate & $\frac{1}{7.9}$ & {$[30,46]$} \\
\hline$\gamma_{h, t}$ & Treatment recovery rate & $\frac{1}{5}$ & {$[33]$} \\
\hline$\mu_{v, i}$ & Insecticide related death rate & 1 & {$[56]$} \\
\hline$\beta_{v h}$ & $\begin{array}{l}\text { Mosquito-to-human transmission } \\
\text { rate (without control) }\end{array}$ & $\frac{1}{11.3}$ & {$[25,30]$} \\
\hline$\beta_{h v}$ & $\begin{array}{l}\text { Human-to-mosquito transmission } \\
\text { rate (without control) }\end{array}$ & $\frac{1}{8.6}$ & {$[25,30]$} \\
\hline$\beta_{h h}$ & $\begin{array}{l}\text { Human-to-human transmission rate } \\
\text { (without control) }\end{array}$ & $\frac{1}{20}$ & {$[33]$} \\
\hline$c_{b}$ & Mosquito bite control & Variable & \\
\hline$c_{c}$ & Contact control & 0.05 & Our estimate \\
\hline$c_{t}$ & Treatment control & 0.05 & Our estimate \\
\hline$c_{i}$ & Insecticide control & 0.005 & Our estimate \\
\hline$\widetilde{\beta}_{v h}\left(c_{b}\right)$ & $\begin{array}{l}\text { Mosquito-to-human transmission } \\
\text { rate with control }\end{array}$ & $\left(1-c_{b}\right) \beta_{v h}$ & \\
\hline$\widetilde{\beta}_{h v}\left(c_{b}\right)$ & $\begin{array}{l}\text { Human-to-mosquito transmission } \\
\text { rate with control }\end{array}$ & $\left(1-c_{b}\right) \beta_{h v}$ & \\
\hline$\widetilde{\beta}_{h h}\left(c_{c}\right)$ & $\begin{array}{l}\text { Human-to-human transmission rate } \\
\text { with control }\end{array}$ & $\left(1-c_{c}\right) \beta_{h h}$ & \\
\hline$\tilde{\gamma}\left(c_{t}\right)$ & Recovery rate with treatment control & $\gamma+c_{t} \gamma_{h, t}$ & \\
\hline$\tilde{\mu}_{v}\left(c_{i}\right)$ & $\begin{array}{l}\text { Mosquito death rate with insecticide } \\
\text { control }\end{array}$ & $\mu_{v}+c_{i} \mu_{v, i}$ & \\
\hline
\end{tabular}

All rates are per capita per day

\subsection{Model Calibration}

We adopt most of the parameter values from [72] who followed [25] who fit the ZIKV transmission model to data from Brazil.

The recruitment rate, $\Lambda_{h}$, in Brazil is 13.92 per year per 1000 people [77]. The life expectancy, $\mu_{h}^{-1}$, in Brazil is 74 years [23]. It takes on average 9.9 days for the infected individual to have no detectable virus in blood [46], the infectiousness of ZIKV infection ends 1.5-2 days before the virus becomes undetectable [30]. Thus, an individual stays infectious for $\gamma^{-1}=7.9$ days [25]. The mean duration of the acute ZIKV phase is 5 days [33], which gives $\gamma_{h, t}=\frac{1}{5}$.

The mosquito recruitment rate, $\Lambda_{v}$, is about 3000 a day [4]. The mosquito life expectancy, $\mu_{v}^{-1}$, is 11 days [60]. This is in line with the life expectancy for mosquitoes in Rio de Janeiro, Brazil [49], and close to the average of 2-3 weeks considered in biological studies [58].

The time between a mosquito being infected and it infecting a human, $\beta_{v h}^{-1}$, is 11.3 days [25], while the time between a human infection and a mosquito taking an infectious blood 
meal, $\beta_{h v}^{-1}$, is and 8.6 days, respectively [30]. The human-to-human transmission rate, $\beta_{h h}$, is $\frac{1}{20}$ [33].

The insecticide related death rate, $\mu_{v, i}$ is 1 , about 10 times the natural mosquito mortality rate, in line with [56].

We estimate the bite control, $c_{b}$ as follows. The population of Brazil is about 209 mil people [77]. In 2015, the revenue from mosquito repellent sales in Brazil was \$55.7 mil [16]. The revenue for 2016 was expected to rise $120 \%$ [16], i.e., to $\$ 122.54$ mil. The most frequent DEET repellents cost about $\$ 4.2$ [53], i.e., about 29.17 mil bottles were sold in 2016. One bottle of DEET contains about 400 sprays [28,54], i.e., lasts about 200 days since, on average, DEET is applied twice a day [53]. At the same time, three applications of DEET per day seem to provide complete protection. We thus get $c_{b}=\left(209 \times 10^{6}\right)^{-1} \cdot\left(29.17 \times 10^{6}\right) \cdot\left(\frac{200}{365}\right) \cdot\left(\frac{2}{3}\right)=$ 0.051 .

We were not able to obtain values of the controls $c_{i}, c_{c}, c_{t}$ from the literature, but we calibrated the model as follows. There were 215319 ZIKV infection cases in 2016 [48,55], i.e., the incidence rate was 103 cases in $10^{5}$ people. Setting $c_{c}=0.05, c_{t}=0.05$ and $c_{i}=0.005$ yielded an incidence rate of 106 cases per $10^{5}$ people and so we adopted those values. We note that there are many other combinations of values that yield the similar incidence rate. However, the main results are quite robust to a particular choice of this combination since similar incidence rates yield similar risks of infections.

Most ZIKV infections are asymptomatic and do not need any extra costs. The cost of a symptomatic ZIKV infection in the US is around \$6355 dollars [45]. The GDP per capita for Brazil is $\$ 15600$ and for the United States is $\$ 59500$ [23]. Therefore, the cost of ZIKV infection in Brazil is estimated as $\$ 1588$.

The cost of mosquito bite prevention by using DEET is estimated as follows. The cost of the most frequently sold DEET is $\$ 4.2$ per bottle [53]. One bottle of DEET contains 400 sprays and at three sprays a day, the cost is about $\$ 0.0315$ per day.

\subsection{Game-Theoretical Framework of Voluntary Bite Protection}

Following [10], we add a game-theoretical component to the compartmental model above. We consider a repeated population game where the payoff to each individual is determined by their own strategy and the average strategy used by the population as a whole.

The players of the game are susceptible individuals who repeatedly choose whether to use DEET or not. We characterize the strategy by a single number $c_{b}$ that specifies a proportion of the time the individual uses DEET. The solution of the game, called the Nash equilibrium, is the population-level value $c_{b, \mathrm{NE}}$ at which no individual can increase their own payoff by deviating from the population strategy.

The payoff to an individual depends on the prevalence of ZIKV in the population, i.e., on the strategies other players are using. To solve for the Nash equilibrium value, we can assume that all players use the same strategy and only the strategy of the focal player may vary. Following [10], we assume that all individuals are provided with the same information such as prevalence of ZIKV in the population, the cost of treatment, and the cost of DEET. We will also assume that they use the information in the same and rational way to assess costs and risks [10]. 
The probability of getting infected when not using DEET at all while everybody else is using it at frequency $c_{b}$ is

$$
\frac{\beta_{v h} \frac{I_{v}}{N_{v}}+\widetilde{\beta}_{h h}\left(c_{c}\right) \frac{I_{h}}{N_{h}}}{\beta_{v h} \frac{I_{v}}{N_{v}}+\widetilde{\beta}_{h h}\left(c_{c}\right) \frac{I_{h}}{N_{h}}+\mu_{h}}
$$

which corresponds to the rate moving from $S_{h}$ to $I_{h}$ (when not using any DEET protection) over the total rate of moving out of $S_{h}$. The probability may (and will) depend on $c_{b}$, because the formula contains $I_{v}$ and $I_{h}$ that may (and will) depend on $c_{b}$. The average cost of not using DEET, $C_{N}$, when everybody else uses it at frequency $c_{b}$ is then given by

$$
C_{N}\left(c_{b}\right)=C_{\text {Zika }} \frac{\beta_{v h} \frac{I_{v}}{N_{v}}+\widetilde{\beta}_{h h}\left(c_{c}\right) \frac{I_{h}}{N_{h}}}{\beta_{v h} \frac{I_{v}}{N_{v}}+\widetilde{\beta}_{h h}\left(c_{c}\right) \frac{I_{h}}{N_{h}}+\mu_{h}} .
$$

In order to determine the expected cost of using DEET, let $C_{\text {DEET }}$ denote the cost of actual use. Because one can still get infected from another human, the probability of infection is

$$
\frac{\widetilde{\beta}_{h h}\left(c_{c}\right) \frac{I_{h}}{N_{h}}}{\widetilde{\beta}_{h h}\left(c_{c}\right) \frac{I_{h}}{N_{h}}+\mu_{h}} .
$$

So, the cost of using DEET, $C_{U}$, when everybody else is using it at frequency $c_{b}$ is given by

$$
C_{U}\left(c_{b}\right)=C_{\mathrm{DEET}}+C_{\mathrm{Zika}} \frac{\widetilde{\beta}_{h h}\left(c_{c}\right) \frac{I_{h}}{N_{h}}}{\widetilde{\beta}_{h h}\left(c_{c}\right) \frac{I_{h}}{N_{h}}+\mu_{h}} .
$$

To get Nash equilibrium, we have to solve

$$
C_{N}\left(c_{b}\right)=C_{U}\left(c_{b}\right)
$$

for $c_{b}$.

\section{Analysis of the ODE System}

There are two equilibria of the differential equations given in (1)-(5). The equilibria and the basic reproduction number were derived in [72]; here we summarize the main results.

\subsection{Disease-free Equilibrium}

The disease-free equilibrium $E^{0}=\left(S_{H}^{0}, I_{H}^{0}, R_{H}^{0}, S_{V}^{0}, I_{V}^{0}\right)$ is given by

$$
E^{0}=\left(\frac{\Lambda_{h}}{\mu_{h}}, 0,0, \frac{\Lambda_{v}}{\widetilde{\mu}_{v}\left(c_{i}\right)}, 0\right) .
$$

The basic reproduction number, $\mathcal{R}_{0}$, is given by

$$
\mathcal{R}_{0}=\frac{1}{\mu_{h}+\widetilde{\gamma}\left(c_{t}\right)} \cdot\left(\widetilde{\beta}_{h h}\left(c_{c}\right)+\frac{\widetilde{\beta}_{h v}\left(c_{b}\right) \widetilde{\beta}_{v h}\left(c_{b}\right)}{\widetilde{\mu}_{v}\left(c_{i}\right)}\right) .
$$

Since system (1)-(5) is a special case of a system considered in [76], Theorems 2.1.1 and 2.1.2 of [76] directly imply that, the disease-free equilibrium is globally asymptotically stable if $\mathcal{R}_{0} \leq 1$. It is unstable if $\mathcal{R}_{0}>1$. 


\subsection{Endemic Equilibrium}

The endemic equilibrium is $E^{*}=\left(S_{h}^{*}, I_{h}^{*}, R_{h}^{*}, S_{v}^{*}, I_{v}^{*}\right)$ where $I_{h}^{*}$ is a positive solution of

$$
a\left(I_{h}^{*}\right)^{2}+b I_{h}^{*}+c=0
$$

with

$$
\begin{aligned}
a= & \left(\frac{\tilde{\gamma}\left(c_{t}\right)+\mu_{h}}{\mu_{h}}\right)\left(\frac{\widetilde{\beta}_{h h}\left(c_{c}\right) \tilde{\beta}_{h v}\left(c_{b}\right)}{N_{h}^{2}}\right) \\
b= & \frac{\widetilde{\gamma}\left(c_{t}\right)+\mu_{h}}{\mu_{h}}\left(\frac{\widetilde{\beta}_{v h}\left(c_{b}\right) \widetilde{\beta}_{h v}\left(c_{b}\right)}{N_{h}}+\frac{\widetilde{\beta}_{h h}\left(c_{c}\right)}{N_{h}} \tilde{\mu}_{v}\left(c_{i}\right)+\frac{\widetilde{\beta}_{h v}\left(c_{b}\right)}{N_{h}} \mu_{h}\right) \\
& -\frac{\widetilde{\beta}_{h h}\left(c_{c}\right) \tilde{\beta}_{h v}\left(c_{b}\right)}{N_{h}} \\
c= & \tilde{\mu}_{v}\left(c_{i}\right)\left(\widetilde{\gamma}\left(c_{t}\right)+\mu_{h}-\widetilde{\beta}_{h h}\left(c_{c}\right)\right)-\widetilde{\beta}_{v h}\left(c_{b}\right) \widetilde{\beta}_{h v}\left(c_{b}\right)
\end{aligned}
$$

and

$$
\begin{aligned}
S_{h}^{*} & =\frac{\Lambda_{h}}{\mu_{h}}-\frac{\left(\widetilde{\gamma}\left(c_{t}\right)+\mu_{h}\right) I_{h}^{*}}{\mu_{h}} \\
R_{h}^{*} & =\frac{\widetilde{\gamma}\left(c_{t}\right)}{\mu_{h}} I_{h}^{*} \\
I_{v}^{*} & =\frac{\Lambda_{v}}{\widetilde{\mu}_{v}\left(c_{i}\right)} \cdot \frac{\widetilde{\beta}_{h v}\left(c_{b}\right) \frac{I_{h}^{*}}{N_{h}}}{\widetilde{\beta}_{h v}\left(c_{b}\right) \frac{I_{h}^{*}}{N_{h}}+\widetilde{\mu}_{v}\left(c_{i}\right)} \\
S_{v}^{*} & =\frac{\Lambda_{v}}{\widetilde{\mu}_{v}\left(c_{i}\right)}-I_{v}^{*} .
\end{aligned}
$$

If $\mathcal{R}_{0}>1$, the endemic equilibrium is unique [72] and locally asymptotically stable [76, Theorem 2.2.1].

\section{Results}

\subsection{Minimal DEET Coverage Needed for ZIKV Elimination}

In this section, we determine $c_{b, \emptyset}$, the minimal coverage at which susceptible individuals should use DEET so that ZIKV is eliminated. It follows from (12) that $\frac{\partial R_{0}}{\partial c_{b}}<0$, i.e., $\mathcal{R}_{0}$ is decreasing in $c_{b}$. Consequently, ZIKV will be eliminated at the smallest value of $c_{b} \in[0,1]$ for which $R_{0} \leq 1$. Note that if $\left.\mathcal{R}_{0}\right|_{c_{b}=1}=\frac{1}{\mu_{H}+\widetilde{\gamma}\left(c_{t}\right)} \cdot \widetilde{\beta}_{h h}\left(c_{c}\right)>1$, then $\mathcal{R}_{0}>1$ for all values of $c_{b}$ and thus ZIKV will never be eliminated. On the other hand, if $\left.\mathcal{R}_{0}\right|_{c_{b}=0}<1$, i.e., $\mathcal{R}_{0}<1$ even when nobody is using DEET, then ZIKV is not endemic. The only non-trivial critical value of $c_{b}$ exists when $\left.\mathcal{R}_{0}\right|_{c_{b}=0}>1$ and $\left.\mathcal{R}_{0}\right|_{c_{b}=1}<1$. By (12) it is given as a solution of

$$
\frac{1}{\mu_{h}+\tilde{\gamma}\left(c_{t}\right)} \cdot\left(\widetilde{\beta}_{h h}\left(c_{c}\right)+\frac{\tilde{\beta}_{h v}\left(c_{b}\right) \widetilde{\beta}_{v h}\left(c_{b}\right)}{\widetilde{\mu}_{v}\left(c_{i}\right)}\right)=1 .
$$




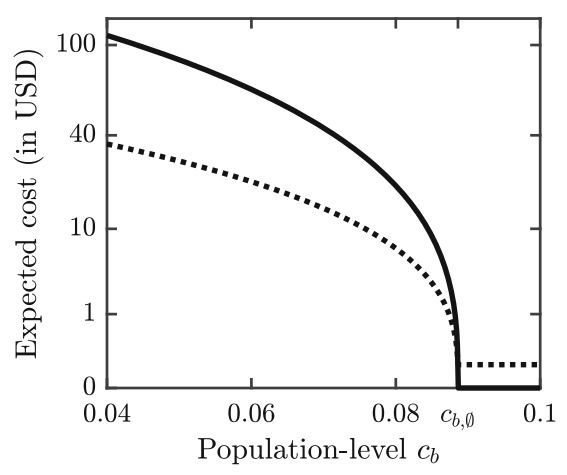

Fig. 2 The expected cost of not using DEET (solid line) and the expected cost of using DEET as a function of population-level DEET coverage in the population. The parameters are as in Table 1. The solid line reaches 0 at $c_{b, \varnothing}$, the level needed for ZIKV elimination. The lines intersect at the Nash equilibrium, $c_{b}$, NE. While $c_{b, \mathrm{NE}}<c_{b, \emptyset}$, we can see that $c_{b, \mathrm{NE}} \approx c_{b, \emptyset}$. In fact, in our model $c_{b, \emptyset}-c_{b, \mathrm{NE}}<10^{-3}$ even when parameter values differ significantly from the values specified in Table 1

Consequently,

$$
c_{b, \emptyset}= \begin{cases}0, & \text { if }\left.\mathcal{R}_{0}\right|_{c_{b}=0}<1, \\ 1-\sqrt{\frac{\left(\mu_{H}+\tilde{\gamma}\left(c_{t}\right)-\widetilde{\beta}_{h h}\left(c_{c}\right)\right) \cdot \tilde{\mu}_{v}\left(c_{i}\right)}{\beta_{v h} \beta_{h v}},} & \text { if }\left.\mathcal{R}_{0}\right|_{c_{b}=0}>1 \text { and }\left.\mathcal{R}_{0}\right|_{c_{b}=1}<1, \\ \text { Does not exist, } & \text { if }\left.\mathcal{R}_{0}\right|_{c_{b}=1}>1 .\end{cases}
$$

\subsection{Nash Equilibrium}

In this section, we are interested in finding $c_{b, \mathrm{NE}}$. We will consider the situation only under the endemic equilibrium (there is no need to use DEET in the disease-free equilibrium).

The graphical solution of $C_{N}\left(c_{b}\right)=C_{U}\left(c_{b}\right)$ where $C_{N}$ and $C_{U}$ are given in (7) and (9) is illustrated in Fig. 2. The numerical solutions are shown in Fig. 3.

For the parameter values in Table 1, the resulting social optimum and Nash equilibrium values are $c_{b, \emptyset}=0.0886$ and $c_{b, \mathrm{NE}}=0.0885$, respectively. The annual incidence rate when individuals use the optimal voluntary level of protection, $c_{b}, \mathrm{NE}$, is $0.2 \mathrm{ZIKV}$ cases per $10^{5}$ people. We can thus see that the disease would be almost eliminated by optimal voluntary use of DEET.

We can also consider the annual incidence rate of 0.2 cases per $10^{5}$ people to be the price of anarchy as if the social optimum, $c_{b, \emptyset}$, was enforced, ZIKV would be eliminated, i.e., the incidence rate would be 0 .

\subsection{Sensitivity Analysis}

The dependence of $c_{b, \mathrm{NE}}$ on parameters is shown in Fig. 3 and the sensitivity indices are presented in Table 2 . The values of $c_{b, \emptyset}$ track closely the values of $c_{b, \mathrm{NE}}$ with only a minimal difference (less than $10^{-3}$ ) between the two.

The optimal voluntary level of protection, $c_{b, \mathrm{NE}}$, is essentially constant in the human recruitment rate $\Lambda_{h}$, the vector recruitment rate $\lambda_{v}$, the human natural death rate $\mu_{h}$, the cost of the prevention, $C_{\mathrm{DEET}}$, and the cost of the disease, $C_{\mathrm{Zika}}$. 

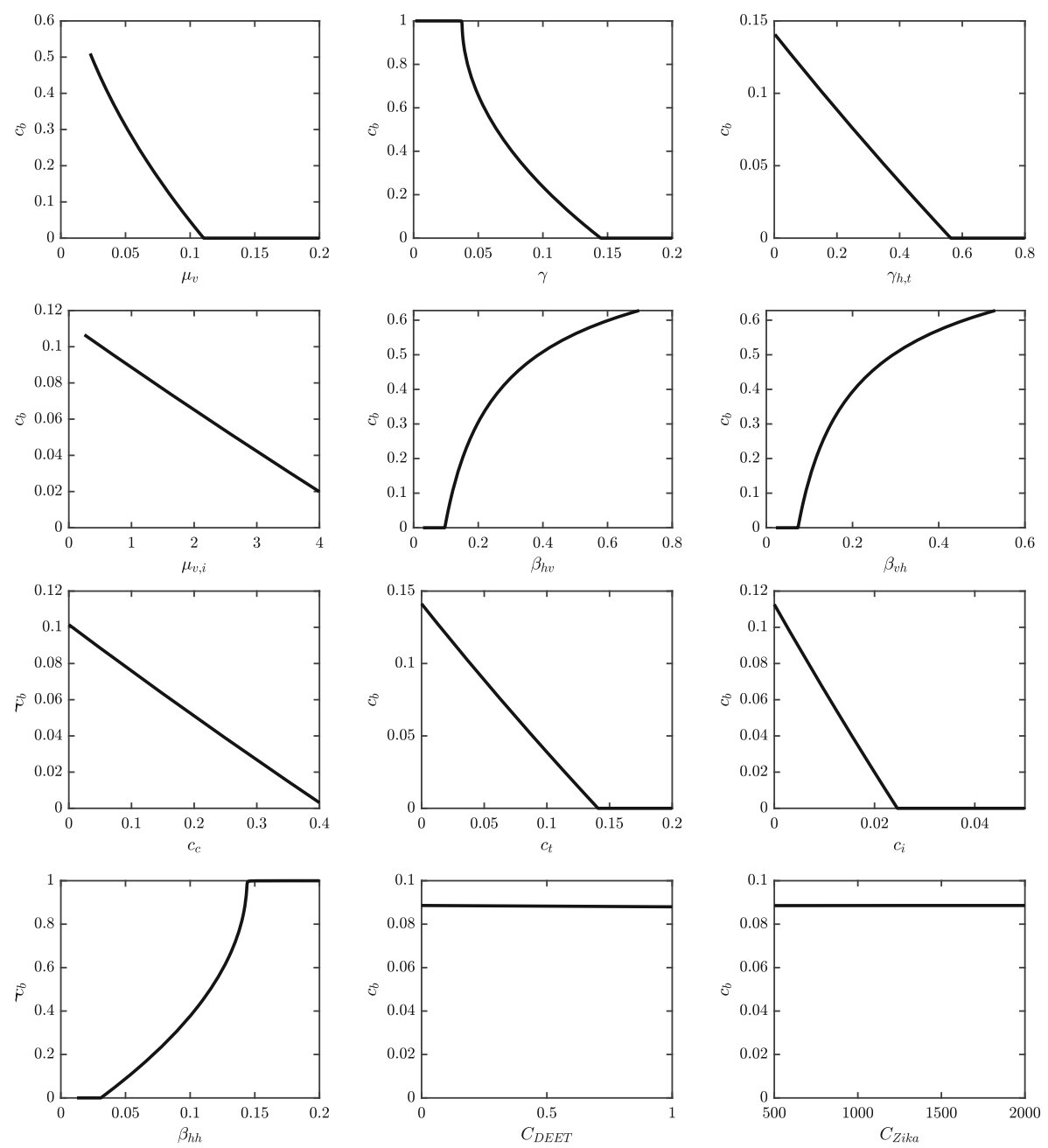

Fig. 3 Dependence of $c_{b}$,NE on different parameter values. Unless varied, the parameter values are as specified in Table 1 . When all parameters are as in Table $1, c_{b, \emptyset}=0.0886$ and $c_{b, \mathrm{NE}}=0.0885$. $c_{b, \mathrm{NE}}$ is constant in $\Lambda_{h}, \Lambda_{v}$ and $\mu_{h}$ and these figures are not shown

Also, $c_{b, \mathrm{NE}}$ increases rapidly with the human-to-vector and vector-to-human transmission rates, $\beta_{h v}$ and $\beta_{v h}$ and it is also increasing in the human-to-human transmission rate $\beta_{h h}$. It is rapidly decreasing in the recovery rate $\gamma$ and the mosquito death rate $\tilde{\mu}_{v}\left(c_{i}\right)$. Correspondingly, $c_{b, \mathrm{NE}}$ is also decreasing in the treatment control $c_{t}$, the insecticide control $c_{i}$ and the contact control $c_{c}$.

\section{Discussion}

One of the interesting predictions of this model is that the optimal voluntary use of DEET does not depend in any significant way on the cost of the prevention. This finding is in sharp 
Table 2 The sensitivity index of $c_{b, \mathrm{NE}}$ on various parameters $p$ calculated as

$\left(\frac{p}{c_{b, \mathrm{NE}}}\right) \cdot\left(\frac{\partial c_{b, \mathrm{NE}}}{\partial p}\right)$, see for example [7]

\begin{tabular}{lr}
\hline Parameter & $S I_{c_{b, \mathrm{NE}}}$ \\
\hline$\beta_{v h}$ & 5.165 \\
$\beta_{h v}$ & 5.165 \\
$\beta_{h h}$ & 2.759 \\
$\Lambda_{h}$ & 0.000 \\
$\Lambda_{v}$ & 0.000 \\
$\mu_{h}$ & 0.000 \\
$C_{\mathrm{Zika}}$ & 0.000 \\
$C_{\mathrm{DEET}}$ & 0.000 \\
$c_{c}$ & -0.155 \\
$\mu_{v, i}$ & -0.270 \\
$c_{i}$ & -0.270 \\
$\gamma_{h, t}$ & -0.564 \\
$c_{t}$ & -0.591 \\
$\mu_{v}$ & -4.847 \\
$\gamma$ & -7.248 \\
\hline
\end{tabular}

The numbers were rounded to three decimal places. Parameters are as specified in Table 1 . The sensitivity index -0.5 means that $1 \%$ increase in a parameter value $p$ will result in a $0.5 \%$ decrease in $c_{b, \mathrm{NE}}$. The sensitivity of $c_{b, \emptyset}$ is identical

contrast to other similar game-theoretical models. For example, as shown in [1], the relatively low cost of a typhoid infection (compared to vaccination cost and effectiveness) is the reason why the vaccination coverage is quite low in rural Ghana. Similarly, even for vector-borne diseases such as Chagas disease, the cost of the insecticide-treated nets significantly affects the optimal usage levels and consequently the disease incidence rate [35].

Another interesting prediction is that the optimal voluntary use of DEET brings ZIKV very close to elimination levels. This agrees with predictions for other vector-borne diseases such as malaria [15], dengue [27], chikungunya [40] and visceral leishmaniasis [31] or diseases like Ebola [13]. In all these cases, cost of disease prevention is low relative to the cost of the disease. This is different in vaccination games for diseases like polio [10,19] and Hepatitis $B$ vaccination $[21,68]$ where either the real or the perceived vaccination costs are relatively large.

The high cost of ZIKV infection can explain why the ZIKV outbreaks, while serious, are still relatively limited. It has been demonstrated that individuals act in a way that maximizes their self-interests, rather than the interests of the entire group [51]. Vaccination in particular and disease prevention in general is prone to free-riding [38]. The "free-riders" avoid the costs associated with the prevention while benefiting from actions taken by others $[18,69,75]$. However, the risk of severe negative ZIKV complications such as Guillain-Barré Syndrome, microcephaly, and other birth defects means that the cost of ZIKV infection is high and thus the individuals want to protect themselves (and their unborn babies) almost regardless of the cost of the protection.

Our model predicted the optimal voluntary use of the repellents at about $8.8 \%$. On one hand, this number seems quite low. Indeed, in Northern Brazil where the ZIKV outbreak originated, the repellent use during 2016 was $83 \%$ among highly educated pregnant women and 56\% among pregnant women overall [53]. However, in the very same region, only 
less than $21 \%$ of women of childbearing age (15-49 years) report having used mosquito repellent or insecticides frequently during 2015-2016 [63]. The economic factor was the main justification for the non-use of repellents both in urban and rural areas [53].

\section{Conclusions}

Mathematical modeling is a useful tool that helps our understandings of how interactions between the population, individuals, and the environment can change the course of a disease [22]. In this paper, we adopted an ODE model of ZIKV transmission dynamics that originated in [12]. We applied a game-theoretical approach, developed by Bauch and Earn [10], and determined the optimal voluntary use of DEET to prevent the spread of ZIKV through vector bites. We also gave formulas for a desired level of DEET usage that leads to ZIKV elimination. Similarly to other recently studied vector-borne diseases, such as dengue [27], malaria [15], visceral leishmaniasis [31] and Chagas [35], we saw that the optimal voluntary use of DEET can significantly contribute to ZIKV elimination. This differs from the predictions for nonvector-borne diseases such as polio [19] and hepatitis B [21] where the optimal voluntary use levels and the levels required for the herd immunity were significantly different.

There are several ways in which our model can be extended. From the game-theoretical perspective, one can apply a multi-agent-simulation (MAS) methodology [5,39,44]. This approach may be fruitful for two reasons: (1) the DEET application needs to be repeated as with the influenza [6], typhoid [1] or hepatitis [21,68] vaccinations, (2) there are multiple ways in which one can get infected and the simulations may provide a more realistic and flexible approach for multiple protective actions. This would also allow the incorporation of game-theoretical component into models like $[2,3,33]$ that distinguish between females and males.

There are four control measures that help ZIKV elimination. An individual generally cannot influence the level of hospital care or any large-scale insecticide spraying to substantially increase mosquito death rates; therefore the control measures related to these are not suitable for game-theoretical analysis. At the same time, the reduction in human-to-human transmission through the use of condoms is something an individual can influence directly. However, even this control is still not an individual's own decision. Unless both individuals agree to use (or not to use) condom, there is no interaction. The proper analysis of the game involving condom use would thus have to take into account a population heterogeneity and contact network structure rather than just simple averages of players' condom usage.

The analysis of game-theoretical models that deal with two or more prevention measures simultaneously seems to be much harder. So far only specific models for COVID-19 with vaccination or social distancing [20] and cholera with vaccination or clean water usage [41] were considered. It would be of a great interest to develop a general framework.

Acknowledgements The authors would like to thank the anonymous reviewers and the guest editors for their constructive feedback and suggestions that helped to improve this manuscript.

Data Availability Data sharing is not applicable to this article as no datasets were generated or analyzed during the current study. 


\section{References}

1. Acosta-Alonzo CB, Erovenko IV, Lancaster A, Oh H, Rychtáŕ J, Taylor D (2020) High endemic levels of typhoid fever in rural areas of Ghana may stem from optimal voluntary vaccination behavior. Proc $\mathrm{R}$ Soc A 476:20200354

2. Agusto FB, Bewick S, Fagan W (2017) Mathematical model of Zika virus with vertical transmission. Infect Dis Model 2(2):244-267

3. Agusto FB, Bewick S, Fagan WF (2017) Mathematical model for Zika virus dynamics with sexual transmission route. Ecol Complex 29:61-81

4. Andraud M, Hens N, Marais C, Beutels P (2012) Dynamic epidemiological models for dengue transmission: a systematic review of structural approaches. PLoS ONE 7(11):e49085

5. Arefin MR, Kabir KA, Tanimoto J (2020) A mean-field vaccination game scheme to analyze the effect of a single vaccination strategy on a two-strain epidemic spreading. J Stat Mech Theory Exp 2020(3):033501

6. Arefin MR, Masaki T, Kabir KA, Tanimoto J (2019) Interplay between cost and effectiveness in influenza vaccine uptake: a vaccination game approach. Proc R Soc A 475(2232):20190608

7. Arriola L, Hyman JM (2009) Sensitivity analysis for uncertainty quantification in mathematical models. In: Mathematical and statistical estimation approaches in epidemiology. Springer, pp 195-247

8. Bankuru SV, Kossol S, Hou W, Mahmoudi P, Rychtár J, Taylor D (2020) A game-theoretic model of Monkeypox to assess vaccination strategies. PeerJ 8:e9272

9. Basso C, da Rosa EG, Lairihoy R, Caffera RM, Roche I, González C, da Rosa R, Gularte A, Alfonso-Sierra E, Petzold M (2017) Scaling up of an innovative intervention to reduce risk of dengue, chikungunya, and zika transmission in Uruguay in the framework of an intersectoral approach with and without community participation. Am J Trop Med Hyg 97(5):1428-1436

10. Bauch CT, Earn DJ (2004) Vaccination and the theory of games. Proc Natl Acad Sci 101(36):13391-13394

11. Bonyah E, Khan MA, Okosun KO, Gómez-Aguilar J (2019) On the co-infection of dengue fever and Zika virus. Optim Control Appl Methods 40(3):394-421

12. Bonyah E, Okosun KO (2016) Mathematical modeling of Zika virus. Asian Pacific J Trop Dis 6(9):673679

13. Brettin A, Rossi-Goldthorpe R, Weishaar K, Erovenko IV (2018) Ebola could be eradicated through voluntary vaccination. R Soc Open Sci 5(1):171591

14. Brooks JT, Friedman A, Kachur RE, LaFlam M, Peters PJ, Jamieson DJ (2016) Update: interim guidance for prevention of sexual transmission of Zika virus-United States, July 2016. Morb Mortal Wkly Report 65(29):745-747

15. Broom M, Rychtár̆ J, Spears-Gill T (2016) The game-theoretical model of using insecticide-treated bednets to fight malaria. Appl Math 7(09):852-860

16. Bruno L (2016) Mosquito repellant sales boom in Brazil amid Zika scare. https://www.reuters.com/article/ health-zika-repellant/mosquito-repellant-sales-boom-in-brazil-amid-zika-scare-idUSL8N15I52T. Accessed 10 Nov 2020

17. Carran S, Ferrari M, Reluga T (2018) Unintended consequences and the paradox of control: management of emerging pathogens with age-specific virulence. PLoS Negl Trop Dis 12(4):e0005997

18. Chang SL, Piraveenan M, Pattison P, Prokopenko M (2020) Game theoretic modelling of infectious disease dynamics and intervention methods: a review. J Biol Dyn 14(1):57-89

19. Cheng E, Gambhirrao N, Patel R, Zhowandai A, Rychtár J, Taylor D (2020) A game-theoretical analysis of Poliomyelitis vaccination. J Theor Biol 499:110298

20. Choi W, Shim E (2020) Optimal strategies for vaccination and social distancing in a game-theoretic epidemiologic model. J Theor Biol 505:110422

21. Chouhan A, Maiwand S, Ngo M, Putalapattu V, Rychtář J, Taylor D (2020) Game-theoretical model of retroactive hepatitis B vaccination in China. Bull Math Biol 82:80

22. Chubb MC, Jacobsen KH (2010) Mathematical modeling and the epidemiological research process. Eur J Epidemiol 25(1):13-19

23. CIA (2020) The world factbook-birth rate. https://www.cia.gov/library/publications/the-worldfactbook/fields/345.html. Accessed 13 Apr 2020

24. Crawford K, Lancaster A, Oh H, Rychtár J (2015) A voluntary use of insecticide-treated cattle can eliminate African sleeping sickness. Lett Biomath 2(1):91-101

25. Dantas E, Tosin M, Cunha A Jr (2018) Calibration of a SEIR-SEI epidemic model to describe the Zika virus outbreak in Brazil. Appl Math Comput 338:249-259

26. Ding C, Tao N, Zhu Y (2016) A mathematical model of Zika virus and its optimal control. In: 201635 th Chinese control conference (CCC). IEEE, pp 2642-2645

27. Dorsett C, Oh H, Paulemond ML, Rychtár J (2016) Optimal repellent usage to combat dengue fever. Bull Math Biol 78(5):916-922 
28. EPA (2020) US Environmental Protection Agency: find the repellent that is right for you. https://www. epa.gov/insect-repellents/find-repellent-right-you. Accessed 10 Nov 2020

29. Fauci AS, Morens DM (2016) Zika virus in the Americas-yet another arbovirus threat. N Engl J Med 374(7):601-604

30. Ferguson NM, Cucunubá ZM, Dorigatti I, Nedjati-Gilani GL, Donnelly CA, Basáñez M-G, Nouvellet P, Lessler J (2016) Countering the Zika epidemic in Latin America. Science 353(6297):353-354

31. Fortunato AK, Glasser CP, Watson JA, Lu Y, Rychtář J, Taylor D (2021) Mathematical modelling of the use of insecticide-treated nets for elimination of visceral leishmaniasis in Bihar, India. R Soc Open Sci $8(6): 201960$

32. Foy BD, Kobylinski KC, Foy JLC, Blitvich BJ, da Rosa AT, Haddow AD, Lanciotti RS, Tesh RB (2011) Probable non-vector-borne transmission of Zika virus, Colorado, USA. Emerg Infect Dis 17(5):880

33. Gao D, Lou Y, He D, Porco TC, Kuang Y, Chowell G, Ruan S (2016) Prevention and control of Zika as a mosquito-borne and sexually transmitted disease: a mathematical modeling analysis. Sci Rep 6:28070

34. Hamel R, Dejarnac O, Wichit S, Ekchariyawat P, Neyret A, Luplertlop N, Perera-Lecoin M, Surasombatpattana P, Talignani L, Thomas F (2015) Biology of Zika virus infection in human skin cells. J Virol 89(17):8880-8896

35. Han CY, Issa H, Rychtáŕ J, Taylor D, Umana N (2020) A voluntary use of insecticide treated nets can stop the vector transmission of Chagas disease. PLOS Negl Trop Dis 14(11):e0008833

36. Hennessey M, Fischer M, Staples JE (2016) Zika virus spreads to new areas-region of the Americas, May 2015-January 2016. Am J Transplant 16(3):1031-1034

37. Honein MA, Dawson AL, Petersen EE, Jones AM, Lee EH, Yazdy MM, Ahmad N, Macdonald J, Evert N, Bingham A et al (2017) Birth defects among fetuses and infants of US women with evidence of possible Zika virus infection during pregnancy. JAMA 317(1):59-68

38. Ibuka Y, Li M, Vietri J, Chapman GB, Galvani AP (2014) Free-riding behavior in vaccination decisions: an experimental study. PLoS ONE 9(1):e87164

39. Kabir KA, Jusup M, Tanimoto J (2019) Behavioral incentives in a vaccination-dilemma setting with optional treatment. Phys Rev E 100(6):062402

40. Klein SRM, Foster AO, Feagins DA, Rowell JT, Erovenko IV (2020) Optimal voluntary and mandatory insect repellent usage and emigration strategies to control the chikungunya outbreak on Reunion Island. PeerJ 8:e10151

41. Kobe J, Pritchard N, Short Z, Erovenko IV, Rychtář J, Rowell JT (2018) A game-theoretic model of cholera with optimal personal protection strategies. Bull Math Biol 80(10):2580-2599

42. Kroeger A, Lenhart A, Ochoa M, Villegas E, Levy M, Alexander N, McCall P (2006) Effective control of dengue vectors with curtains and water container covers treated with insecticide in Mexico and Venezuela: cluster randomised trials. BMJ 332(7552):1247-1252

43. Kucharski AJ, Funk S, Eggo RM, Mallet H-P, Edmunds WJ, Nilles EJ (2016) Transmission dynamics of Zika virus in island populations: a modelling analysis of the 2013-14 French Polynesia outbreak. PLoS Negl Trop Dis 10(5):e0004726

44. Kuga K, Tanimoto J, Jusup M (2019) To vaccinate or not to vaccinate: a comprehensive study of vaccination-subsidizing policies with multi-agent simulations and mean-field modeling. $\mathrm{J}$ Theor Biol 469:107-126

45. Lee BY, Alfaro-Murillo JA, Parpia AS, Asti L, Wedlock PT, Hotez PJ, Galvani AP (2017) The potential economic burden of Zika in the continental United States. PLoS Negl Trop Dis 11(4):e0005531

46. Lessler J, Ott CT, Carcelen AC, Konikoff JM, Williamson J, Bi Q, Kucirka LM, Cummings DA, Reich NG, Chaisson LH (2016) Times to key events in Zika virus infection and implications for blood donation: a systematic review. Bull World Health Organ 94(11):841

47. Li Y, Liu X (2020) Modeling and control of mosquito-borne diseases with Wolbachia and insecticides. Theor Popul Biol 132:82-91

48. Lowe R, Barcellos C, Brasil P, Cruz OG, Honório NA, Kuper H, Carvalho MS (2018) The zika virus epidemic in Brazil: from discovery to future implications. Int J Environ Res Public Health 15(1):96

49. Maciel-De-Freitas R, Codeco CT, Lourenco-De-Oliveira R (2007) Daily survival rates and dispersal of Aedes aegypti females in Rio de Janeiro, Brazil. Am J Trop Med Hyg 76(4):659-665

50. Martinez A, Machado J, Sanchez E, Erovenko I (2019) Optimal vaccination strategies to reduce endemic levels of meningitis in Africa. Preprint

51. Maskin E (1999) Nash equilibrium and welfare optimality. Rev Econ Stud 66(1):23-38

52. Maxian O, Neufeld A, Talis EJ, Childs LM, Blackwood JC (2017) Zika virus dynamics: when does sexual transmission matter? Epidemics 21:48-55

53. Melo VD, Silva JS, La Corte R (2019) Use of mosquito repellents to protect against Zika virus infection among pregnant women in Brazil. Public Health 171:89-96 
54. Miller P (2004) Avoiding the bite: update on DEET: safe and effective against West Nile virus when properly used. Can Pharm J/Rev Pharm Can 137(5):44-47

55. Ministério da Saúde Brasília (2017) Secretaria de vigilância em saúde-ministério da saúde monitoramento dos casos de dengue, febre de chikungunya e febre pelo vírus zika até a semana epidemiológica 52, 2016. Bol Epidemiol 48(3):1-11

56. Momoh AA, Fügenschuh A (2018) Optimal control of intervention strategies and cost effectiveness analysis for a Zika virus model. Oper Res Health Care 18:99-111

57. Nahlen BL, Clark JP, Alnwick D (2003) Insecticide-treated bed nets. Am J Trop Med Hyg 68(4_suppl):12

58. Nelson MJ (1986) Aedes aegypti: biology and ecology. Pan American Health Organization, Washington

59. Oduyebo T, Petersen EE, Rasmussen SA, Mead PS, Meaney-Delman D, Renquist CM, Ellington SR, Fischer M, Staples JE, Powers AM (2016) Update: interim guidelines for health care providers caring for pregnant women and women of reproductive age with possible Zika virus exposure-United States, 2016. Morb Mortal wkly Rep 65(5):122-127

60. Otero M, Solari HG, Schweigmann N (2006) A stochastic population dynamics model for Aedes aegypti: formulation and application to a city with temperate climate. Bull Math Biol 68(8):1945-1974

61. Padmanabhan P, Seshaiyer P, Castillo-Chavez C (2017) Mathematical modeling, analysis and simulation of the spread of Zika with influence of sexual transmission and preventive measures. Lett Biomath 4(1):148-166

62. Petersen LR, Jamieson DJ, Powers AM, Honein MA (2016) Zika virus. N Engl J Med 374(16):1552-1563

63. Quintana-Domeque C, Carvalho JR, de Oliveira VH (2018) Zika virus incidence, preventive and reproductive behaviors: correlates from new survey data. Econ Hum Biol 30:14-23

64. Robert MA, Christofferson RC, Silva NJ, Vasquez C, Mores CN, Wearing HJ (2016) Modeling mosquitoborne disease spread in US urbanized areas: the case of dengue in Miami. PLoS ONE 11(8):e0161365

65. Robert MA, Christofferson RC, Weber PD, Wearing HJ (2019) Temperature impacts on dengue emergence in the United States: investigating the role of seasonality and climate change. Epidemics 28:100344

66. Robert MA, Stewart-Ibarra AM, Estallo EL (2020) Climate change and viral emergence: evidence from Aedes-borne arboviruses. Curr Opin Virol 40:41-47

67. Scheckelhoff K, Ejaz A, Erovenko IV (2019) A game-theoretic model of optimal clean equipment usage to prevent hepatitis $\mathrm{C}$ among injecting drug users. Preprint

68. Scheckelhoff K, Ejaz A, Erovenko IV, Rychtář J, Taylor D (2021) Optimal voluntary vaccination of adults and adolescents can help eradicate hepatitis B in China. Games 12(4):82

69. Serpell L, Green J (2006) Parental decision-making in childhood vaccination. Vaccine 24(19):4041-4046

70. Sykes D, Rychtár J (2015) A game-theoretic approach to valuating toxoplasmosis vaccination strategies. Theor Popul Biol 105:33-38

71. Tang B, Xiao Y, Wu J (2016) Implication of vaccination against dengue for Zika outbreak. Sci Rep $6: 35623$

72. Taylor D (2021) Mathematical model of Zika virus transmission and control measures. N C J Math Stat $7: 1-12$

73. Turelli M, Barton NH (2017) Deploying dengue-suppressing Wolbachia: robust models predict slow but effective spatial spread in Aedes aegypti. Theor Popul Biol 115:45-60

74. Valega-Mackenzie W, Ríos-Soto KR (2018) Can vaccination save a Zika virus epidemic? Bull Math Biol 80(3):598-625

75. Verelst F, Willem L, Beutels P (2016) Behavioural change models for infectious disease transmission: a systematic review (2010-2015). J R Soc Interface 13(125):20160820

76. Wei H-M, Li X-Z, Martcheva M (2008) An epidemic model of a vector-borne disease with direct transmission and time delay. J Math Anal Appl 342(2):895-908

77. World Bank (2020) Life expectancy at birth. https://data.worldbank.org/indicator/SP.DYN.LE00.IN? cid=GPD_10. Accessed 13 Apr 2020

Publisher's Note Springer Nature remains neutral with regard to jurisdictional claims in published maps and institutional affiliations. 